\title{
Mucosal resident memory CD4 T cells in protection and immunopathology
}

\author{
Damian Lanz Turner ${ }^{1,2}$ and Donna L. Farber ${ }^{1,3,4}$ * \\ 1 Columbia Center for Translational Immunology, Columbia University Medical Center, New York, NY, USA \\ 2 Department of Medicine, Columbia University Medical Center, New York, NY, USA \\ ${ }^{3}$ Department of Surgery, Columbia University Medical Center, New York, NY, USA \\ ${ }^{4}$ Department of Microbiology and Immunology, Columbia University Medical Center, New York, NY, USA
}

\section{Edited by:}

Kimberly Sue Schluns, University of Texas MD Anderson Cancer Center, USA

\section{Reviewed by:}

David Hildeman, Cincinnati Children's Hospital, USA

Shahram Salek-Ardakani, University of Florida, USA

Tara Marlene Strutt, University of Massachusetts Medical School, USA

${ }^{*}$ Correspondence:

Donna L. Farber, Columbia Center for Translational Immunology, Columbia University Medical Center, 650 West 168th Street, BB15, New York, NY 10032, USA

e-mail:df2396@cumc.columbia.edu
Tissue-resident memory T cells (TRM) comprise a newly defined subset, which comprises a major component of lymphocyte populations in diverse peripheral tissue sites, including mucosal tissues, barrier surfaces, and in other non-lymphoid and lymphoid sites in humans and mice. Many studies have focused on the role of CD8TRM in protection; however, there is now accumulating evidence that CD4 TRM predominate in tissue sites, and are integral for in situ protective immunity, particularly in mucosal sites. New evidence suggests that mucosal CD4 TRM populations differentiate at tissue sites following the recruitment of effector T cells by local inflammation or infection. The resulting TRM populations are enriched in T-cell specificities associated with the inducing pathogen/antigen. This compartmentalization of memory $T$ cells at specific tissue sites may provide an optimal design for future vaccination strategies. In addition, emerging evidence suggests that CD4 TRM may also play a role in immunoregulation and immunopathology, and therefore, targeting TRM may be a viable therapeutic approach to treat inflammatory diseases in mucosal sites. This review will summarize our current understanding of CD4TRM in diverse tissues, with an emphasis on their role in protective immunity and the mechanisms by which these populations are established and maintained in diverse mucosal sites.

Keywords: mucosal immunity, T-cell memory, intestine, lung, tissue homing

\section{INTRODUCTION}

The anatomic complexity of vertebrates necessitates an immune defense system, which provides protection at diverse sites of pathogen encounter. Earlier views of the immune system as a circulating, surveilling defense force have been supplanted by more recent evidence that the immune response is both localized and adapted to specific anatomic compartments. For T lymphocytes, seminal work by Leo Lefrançois and colleagues first revealed that virus-specific CD8 $\mathrm{T}$ cells that were generated and maintained as long-lived memory $\mathrm{T}$ cells after infection could be maintained in multiple tissue sites throughout the body (1). Subsequent studies using parabiosis models provided early evidence that certain tissues such as intestines contained populations of memory CD8 $\mathrm{T}$ cells that did not readily circulate (2). In recent years, noncirculating populations of memory CD8 T cells have been identified in skin, lung, vaginal mucosa, brain, and even in lymphoid tissues (3-7), which are collectively referred to as "Tissue-resident" memory CD8 T cells (CD8 TRM) $(8,9)$. TRM are populations of clonally expanded memory $\mathrm{T}$ cells that permanently reside in peripheral tissues, are maintained independently of lymphoid and circulating memory T-cell populations, and have the ability to respond rapidly to re-exposure to cognate antigen.

While most studies in mouse models of infection have focused on memory CD8 T-cell generation and maintenance to virus infection, less is understood about memory $\mathrm{CD} 4 \mathrm{~T}$ cells and their role in protection and in tissue-specific responses. In both mice and humans, CD4 T cells are the most abundant lymphocytes throughout the body; they predominate in lymphoid tissue and memory CD4 T cells also outnumber memory CD8 T cells in mucosal tissues and barrier surfaces (10-12). Tissue-resident CD4 TRM have been identified in the lung, skin, and mucosal surfaces, and function to direct protective responses and coordinate recruitment of immune cells to tissues sites $(7,12-15)$. In addition to protective responses, there is also potential in any in situ immune response for collateral tissue damage, resulting in immunopathology. Since tissue-specific inflammatory disease can be driven by CD4 T-cell responses, the contribution of tissue-resident memory T-cell responses in these contexts is important to consider. In this review, we will focus on the role of CD4 TRM in immune responses, both protective and pathogenic and discuss current research and models for their generation and maintenance.

\section{ANATOMIC HETEROGENEITY OF MEMORY CD4 T CELLS: EARLY STUDIES}

The effectiveness of T-cell mediated immunity against pathogens is partly derived from the wide distribution throughout the body of a large repertoire of individual T-cell clones with the ability to recognize and mount an effector response to a large number of pathogen-associated antigenic signatures. Naïve T cells express chemokine receptors such as CCR7 and L-selectin (CD62L) that target their migration from circulation through lymphoid tissue. This circulatory pattern provides the greatest probability of 
encounter of naïve $\mathrm{T}$ cells with their cognate antigens, which are presented by mature antigen presenting cells (APC) that ferry antigen from peripheral tissue to lymph nodes. Upon activation by antigen, naïve cells clonally expand and acquire effector properties, and in the process, upregulate expression of integrins and chemokine receptors that direct migration and access to inflamed peripheral tissues. During the ongoing immune response, effector cells are thus present in both lymphoid organs and peripheral tissues. While the majority of these activated and effector $\mathrm{T}$ cells die after antigen clearance, a proportion persists and develops into long-lived memory T cells.

The identification of memory CD4 T-cell heterogeneity in humans and mice based on homing receptor expression 15 years ago provided the initial evidence that $\mathrm{T}$-cell memory was anatomically diverse. In humans, heterogeneity in CCR7 expression was identified among $\mathrm{CD}_{4} \mathrm{RO}^{+}$memory CD4 $\mathrm{T}$ cells in blood in a landmark study, which designated the CCR7 ${ }^{\text {hi }}$ memory subset as central-memory (TCM) and the CCR7 ${ }^{\text {lo }}$ memory subset as effector-memory (TEM) $(16,17)$. There were also early indications of memory T-cell heterogeneity in mice based on CD62L expression in antigen-specific memory CD4 T cells generated from virus infection or peptide-specific priming, giving rise to $\mathrm{CD} 62 \mathrm{~L}^{\text {lo }}$ and CD62L ${ }^{\text {hi }}$ memory subsets (18-20).

Anatomic heterogeneity of memory CD4 T cells was subsequently demonstrated in mouse models and some human studies. Jenkins and colleagues showed in whole mouse studies that memory CD4 T cells generated in response to peptide immunization were found in both lymphoid and non-lymphoid sites, including in lung, liver, intestines, and salivary glands (21). Other studies identified antigen-specific memory CD4 T cells in mouse lungs following respiratory virus infection (22), or from adoptive transfer of effector cells (23). Similarly, memory CD4 T cells were identified in mouse bone marrow (24), female reproductive tract (FRT) (25), and skin (26). Similarly, early studies in human tissue identified memory CD4 T cells in tonsils and non-lymphoid tissues isolated from surgical explants (27). Additional populations of human memory CD4 T cells were also identified in skin (28) and cerebrospinal fluid (29). These initial findings suggested that memory $\mathrm{T}$ cells may circulate through multiple and diverse sites. However, early evidence of phenotypic and functional distinction between memory CD4 T cells in tissues compared to those in spleen or circulation $(23,28)$, suggested that these tissue memory populations may be maintained independent of their counterparts in circulation.

Several new technological approaches were subsequently implemented to study whether memory $\mathrm{T}$ cells could take up residence and be retained in tissue sites as well as to distinguish circulating from tissue-resident memory T cells. Parabiosis experiments in which mouse pairs are surgically conjoined to create shared circulations provided direct evidence for memory CD4 T cells retained in lung tissues (13), and for memory CD8 T cells resident in intestines and skin $(2,3)$. Imaging via confocal or intravital microscopy also demonstrated that specific $\mathrm{T}$ cells are localized in niches within tissues $(12,30,31)$. However, it is still difficult to assess whether immune cells isolated from peripheral tissues are present within microcapillaries of the tissues or are resident within the tissue. To overcome this problem, an increasing number of studies have used in vivo antibody labeling of $\mathrm{T}$ cells with a fluorescently labeled antibody prior to tissue harvest, such that T-cell accessible to circulation become labeled in vivo with antibody, while those within tissues and not in circulation are protected by in vivo labeling $(6,12,13,32)$. In response to infection, memory CD4 T cells that are protected from in vivo antibody labeling have been identified in lungs following respiratory infection with influenza virus, Mycobacterium tuberculosis (Mtb), and systemic infection with $\operatorname{LCMV}(12,13,15,32)$. When combined with imaging approaches, both circulating and resident memory CD4 T cells can be identified in mouse lungs and spleen. In the following sections, we present the current state of knowledge about CD4 TRM in general and the specific role of CD4 TRM in mucosal sites.

\section{RESIDENT MEMORY CD4 T CELLS AND PROTECTIVE IMMUNITY \\ CD4 TRM: GENERAL PROPERTIES}

CD4 TRM are defined as non-circulating, memory CD4 T cells that are not readily accessible to the vasculature and are retained locally in specific tissue sites. Phenotypically, mouse CD4 TRM are distinguished from circulating TEM populations based on upregulated expression of the early activation marker CD69 and the integrin CD11a $(12,13,33)$. CD69 ${ }^{+}$memory CD4 T cells have been identified in mouse lungs, skin, and intestine, while spleen contains only a minority proportion of $\mathrm{CD} 9^{+}$memory CD4 T cells $(12,13)$. In humans, CD4 TEM phenotype cells in lungs, intestines, lymph nodes, and bone marrow express CD69, with 50-60\% of spleen CD4 TEM expressing CD69, while TEM circulating in blood uniformly lack CD69 expression $(10,34,35)$. The specific upregulation of CD69 by tissue memory CD4 T cells suggests that memory CD4 T cells in human tissues perceive distinct signals compared to those circulating in blood (36). While CD8 TRM are also characterized by upregulation of the $\alpha_{\mathrm{E}}$ integrin, CD103 (9), CD4 TRM in mucosal and lymphoid sites in human and mice generally do not express CD103 $(12,36)$, except for a proportion of skin memory CD4 T cells (31). Whether CD4 TRM in specific sites express other tissue-specific or TRM-specific integrins or adhesion markers is not known, although expression of the collagen-binding integrins VLA- 1 and $\alpha 2$ are associated with lung effector CD4 T-cell responses and bone marrow memory CD4 T cells, respectively $(37,38)$. Functionally, CD4 TRM exhibit rapid recall function and can produce IFN- $\gamma$ and IL-17 in mucosal sites, although the extent to which their functional profile differs from circulating memory populations is not well characterized.

These observations support the general concept that TRM are an effective first line of defense against invading pathogens due to their localization in mucosal tissues that are frequently the sites of infection. TRM populations are likely derived from clonally expanded populations of effector $\mathrm{T}$ cells responding to an infection, and therefore, contain relatively high frequencies of T-cell clones specific for pathogens that target individual tissue sites. This emerging hypothesis postulates that while TRM provide an immediate in situ immune response to infection, TCM and TEM located in lymphoid organs provide a delayed response due to their reliance on migration of APCs for the initiation of the response. The relative contribution of each component to 
conferring protective immunity will probably differ based on the tissue(s) that is infected and the nature of the pathogen; however, this is currently a major research focus. Our knowledge of CD4 TRM and their properties is quickly expanding and it is likely that they will be identified in additional tissues and implicated in immune protection against a variety of tissue-tropic pathogens. A summary of current observations of CD4 TRM in mucosal sites and their protective capacities in different pathogen models is presented in Table 1.

\section{LUNG CD4 TRM}

The lung or respiratory tract is a major site for entry of viral and bacterial pathogens, with respiratory infections constituting the most prevalent cause of illness globally and throughout an individual's lifetime. It has been known for some time that respiratory viral infections induce TEM populations within the lung that display an activated phenotype (47), and that these populations persist within the lung tissue and the lung airways following infection (22). Due to the possible inclusion of cells within the microcapillaries of the lung, these previous studies found phenotypic heterogeneity among lung memory CD4 T-cell isolated from digested tissue (48). Introduction of virus-specific memory CD4 T cells directly into the respiratory tract by intranasal delivery, provided protection to secondary virus challenge (22); however, it was not established whether these protective subsets were circulating or remained resident in lung tissue.

CD4 TRM in the lung were the first resident memory CD4 Tcell population to be extensively characterized and demonstrated to exhibit protective function. Using the in vivo labeling technique to analyze lung memory T-cell populations following influenza virus infection, we found that CD4 TRM were phenotypically distinct from circulating TEM populations in their expression of high levels of CD69 and CD11a, and in their residence in a distinct niche of the lung near airways (12). Further evidence of distinct properties of lung effector-memory $\mathrm{T}$ cells come from adoptive transfer and parabiosis experiments. These studies showed that lung memory CD4 T cells specifically migrate back to the lung following adoptive transfer into congenic hosts while spleen-derived memory CD4 T cells migrate into multiple tissues (13). Parabiosis further revealed that lung memory CD4 T cells were specifically retained in lungs while spleen-derived memory CD4 T cells freely recirculated among multiple lymphoid tissues and entered the lung, but were not retained there (13). Moreover, lung CD4 TRM generated following influenza infection were maintained longterm and were unperturbed in the presence of inhibitors of lymphoid egress and inducers of lymphopenia (12). Similarly, Mtb infection in mice resulted in generation of lung-tropic and retentive CD4 TRM as well as circulating TEM cells (15). Moreover, human memory CD4 T cells in lung are predominantly a TEM phenotype with upregulated expression of CD69 $(10,34)$. Together, these studies identified a new subset of lung CD4 TRM with distinct phenotypic, migration, retention, and maintenance properties.

In experimental models of respiratory infection with influenza, parainfluenza virus, and Mtb, the resulting lung TRM population is enriched with pathogen-specific CD4 $(12,15,49)$ and CD8 T cells (12). Likewise, the lungs of human subjects that had been exposed to Mtb contain resident memory CD4 T cells that were specific for Mtb antigens (50). CD8 T cells specific for influenza and respiratory syncytial virus are found in higher frequencies within human lungs than in the spleen, blood, and skin $(12,34$, 39). While it is possible to determine Mtb exposure by a PPD skin test, it is difficult to document the history of influenza and parainfluenza virus infection in human subjects. The high prevalence of IAV infection among the population, however, suggests that the

Table 1 | Observations of CD4 TRM in mucosal tissues

\begin{tabular}{|c|c|c|c|}
\hline Tissue & Pathogen/antigen & Features & Reference \\
\hline \multirow[t]{10}{*}{ Lung } & Influenza virus & $\mathrm{CD}^{+}{ }^{+}$, cluster around airways & $(12,13)$ \\
\hline & & Unaffected by FTY720 treatment & \\
\hline & & Lung-tropic, protect against second infection & \\
\hline & Influenza virus (humans) & Virus-specific memory CD4 T cells enriched in lung, CD69+, VLA-1+ & $(34,39)$ \\
\hline & Mycobacterium tuberculosis & $\mathrm{CD}_{69}{ }^{+}, \mathrm{CXCR} 3^{\mathrm{hi}}, \mathrm{PD}-1^{\mathrm{hi}}, \mathrm{KLRG} 1^{\mathrm{lo}}$, lung-tropic. Protect against second infection & $(15)$ \\
\hline & Mycobacterium tuberculosis & Lung CD4 TRM generated by BCG vaccination & $(40)$ \\
\hline & & CD4 TRM enhances $\mathrm{MHC}$ II on lung macrophages during $2^{\circ}$ challenge & \\
\hline & Nippostrongylus brasiliensis & Pathogen-specific production of IL-4 and IL-13 & $(41)$ \\
\hline & & Lung TRM unaffected by FTY720 treatment & \\
\hline & & Protect against second infection & \\
\hline \multirow[t]{3}{*}{$\begin{array}{l}\text { Female genital } \\
\text { tract }\end{array}$} & $\begin{array}{l}\text { Herpes simplex virus } \\
\text { (humans) }\end{array}$ & $\begin{array}{l}\text { Enrichment of antigen-specific CD4 T-cell clones in cervical cytobrush specimens } \\
\text { and genital lesions }\end{array}$ & $(42,43)$ \\
\hline & Herpes simplex virus (mice) & CD4 TRM generated in vaginal mucosa (no CD8) & $(44)$ \\
\hline & & IFN- $\gamma$-mediated protection against $2^{\circ} \mathrm{HSV}$ challenge & \\
\hline \multirow[t]{2}{*}{ Gut } & Listeria monocytogenes & $\begin{array}{l}\text { Primary and second oral infection Listeria generates long-lived antigen-specific } \\
\text { T-cell population in LP }\end{array}$ & $(45)$ \\
\hline & N/A & $\begin{array}{l}\text { Homeostatic proliferation of naïve CD4 T cells in MLN generates gut-tropic, } \\
\alpha_{4} \beta_{7}+, T_{H} 17 \text { cells }\end{array}$ & $(46)$ \\
\hline
\end{tabular}


compartmentalization of IAV-specific T cells within the lung is likely a consequence of local infection.

The elevated precursor frequency of pathogen-specific cells in the lung is thought to direct an early in situ immune response against secondary infection. In support of this hypothesis, it has been reported that there is local activation and expansion of memory CD4 T cells in the lung upon secondary IAV challenge (49). We have likewise found that lung CD4 TRM can produce effector cytokines at early time points following secondary viral infection (33). Rapid recall of memory CD4 T cells in the lung has also been suggested as being integral for protection against Mtb in both mouse and human studies (50-52). Lung CD4 TRM in mice were found to mediate superior protective responses to influenza virus challenge compared to spleen-derived memory CD4 T cells (13). Interestingly, influenza-specific lung CD4 TRM protected from morbidity of infection while also mediating rapid viral clearance, and carried out these functions in situ without extensive proliferative expansion or migration to other sites (13). In a mouse Mtb infection model, CD4 TRM cells conferred better protection from secondary Mtb infection in susceptible hosts than their circulating intravascular counterparts (15). The mechanisms for protection by CD4 TRM in the lung have not yet been elucidated. While IFN$\gamma$ is important for memory CD4 T-cell-mediated recall responses to influenza $(53,54)$, protection for Mtb was not associated with IFN- $\gamma$ production (15).

In humans, protection due to resident $\mathrm{T}$ cells is difficult to assess. One group has used the novel approach of bronchoscopic antigen challenge with purified protein derivative of Mtb (PPD) to assess the role that local lung memory $\mathrm{T}$ cells play in the secondary immune response to $\mathrm{Mtb}$ infection. By comparing the local lung immune response (after bronchoscopic challenge) of healthy individuals with a positive PPD skin test to healthy PPD negative controls they observed rapid mobilization of CD4 T cells into the lung airways $(48 \mathrm{~h})$ resulting in a significant increase in antigenspecific T cells (55). These early responding cells did not undergo proliferative expansion as assessed by Ki67 staining, suggesting that they may represent lung TRM cells that migrate into the airways in response to antigen challenge (55). Together, these findings indicate the importance of lung TRM in protecting against respiratory infections, suggesting that targeting generation of persisting CD4 TRM in the lung would provide optimal protection.

\section{REPRODUCTIVE TRACT MUCOSAL CD4 TRM}

The mucosal surfaces of the male and FRT are major sites of entry for sexual transmitted diseases such as herpes simplex virus (HSV), Neisseria gonorrhoeae, human papillomavirus, and human immunodeficiency virus (HIV) - all of great public health concern. The reproductive tract is also prone to opportunistic fungal and bacterial infections with increased incidence in immunocompromised (56) and immunosuppressed patients (57), indicating a role for T-cell mediated immunity in preventing these infections. CD4 T cells are thought to be especially important in controlling genital HSV-2 infection, with mouse studies showing that CD8 deficient mice can be successfully vaccinated against disease while CD4 deficient strains are not $(58,59)$. The importance of CD4 T cells in protection against HSV-2 was supported by the finding that intravaginal HSV-2 infection generates CD4 TRM but little CD8
TRM. These vaginal mucosal memory CD4 T cells in the FRT are sufficient for protective responses to HSV (44) even in the absence of CD8 T cells. In humans, CD4 T cells specific for multiple viral epitopes localize to the uterine cervix $(42,43,60)$ and this resident population is thought to limit the severity of recurrent HSV infections (43). As is the case with HSV-2, pre-existing CD4 TRM cells in the RT may be important for conferring protection against other infections of the urogenital tract such as $N$. gonorrhoeae, Chlamydia muridarum, and Candida infections (61-64).

The relative contribution of CD4 and CD8 T cells in providing protective immunity in the reproductive tract can vary based on the nature of the invading pathogens; however, new studies indicate that CD4 and CD8 TRM can provide early in situ immune responses to infection of the FRT. CD8 TRM have been targeted in the quest to develop a vaccine against HIV because CTLs are thought to be most important for killing virally infected cells. Nonhuman primate models reveal that the simian immunodeficiency virus (SIV) establishes a small founder population of infected cells in the local tissue after infection $(65,66)$. This founder population serves as an expanding source of virus that contributes to virus dissemination (66), and presents an opportunity for total elimination of mucosal viral infections during a narrow window of time early after infection. This task may require early in situ immune responses mounted by local TRM populations.

\section{CD4 TRM IN THE INTESTINES}

The intestinal mucosa is a major interface where the body is exposed to environmental antigens, including benign food antigens, beneficial commensal microorganisms as well as dangerous pathogens. Within the intestine are multiple specialized populations of adaptive and innate immune cells that contribute to various immune functions including: oral tolerance to food antigens, tolerance of commensals, and protective immunity against enteric pathogens (67). These populations include memory CD4 $\mathrm{T}$ cells, some of which are permanently resident CD4 TRM. Gut $\mathrm{T}$ cells are distributed throughout the organized lymphoid tissues that are found throughout the intestines including: Peyers patches, gut-associated lymphoid tissue (GALT), and isolated lymphoid follicles $(68,69)$. Additionally, gut T cells are also found diffused throughout the lamina propria (LP) and within the intraepithelial (IEL) compartment. The majority of the IEL $\mathrm{T}$ cells are $\mathrm{CD}{ }^{+}$ T cells that also express CD103 (70-72) with a lower proportion of CD4 T cells in the IEL compartment. However, CD4 T cells comprise the majority of T cells in the LP and they express an effector-memory phenotype (CD62 $\mathrm{L}^{\text {lo }} \mathrm{CD} 44^{\text {hi }}$ ) (67). In humans, the vast majority of memory CD4 T cells in healthy small and large intestines express CD69, the putative TRM marker (10).

Intestinal resident memory CD4 T-cell populations are shaped by commensal bacterial species. One particular commensal microbe, segmented filamentous bacteria (SFB), was recently shown to induce $T_{H} 17$ cells in the LP of mice $(73,74) . T_{H} 17$ cells provide mucosal immunity against bacterial pathogens through the production of IL-17 and IL-22 $(73,74)$. In addition to $\mathrm{T}_{\mathrm{H}} 17$ cells, commensal bacteria induce resident $\mathrm{T}$-cell populations with regulatory function. Studies have shown that a significant proportion of $\mathrm{T}_{\text {regs }}$ in the intestines are conventional $\mathrm{T}$ cells that are converted to a regulatory phenotype in response to the commensal 
bacterium of the intestinal microbiota (75). Further research revealed specific strains of Clostridium, within mouse intestinal commensals, which were sufficient to induce gut resident $\mathrm{T}_{\text {regs }}$ in mice (76). This group further showed that a selected mixture of Clostridia strains from the human microbiota also induced $\mathrm{T}_{\text {regs }}$ in mice after colonization of the intestines (77). Gut infections with pathogenic bacteria, likewise, induce CD4 TRM populations within the LP. In experimental systems, memory CD4 T cells in the LP are induced by oral infection with bacterial pathogens like Listeria monocytogenes (45).

Studies have employed parabiosis and tissue-grafting approaches to show that gut $\mathrm{T}$-cell populations are maintained independently of systemic populations $(2,78,79)$. The mucosal immune system of the gastrointestinal tract is a compartmentalized division, including resident memory $\mathrm{T}$-cell populations with both pro- and anti-inflammatory functions, which provide important functions for the physiology of the intestines. It has been shown that gut APCs acquire antigen and migrate to the draining mesenteric lymph nodes where they activate $\mathrm{T}$ cells, imprinting the resulting effector and memory $\mathrm{T}$ cells to migrate specifically back into the intestines from circulation (80). This migration tropism of gut memory CD4 T cells is similar to that observed with lung CD4 TRM, and may be a distinguishing feature of mucosal CD4 TRM.

\section{TRM IN CHRONIC INFLAMMATORY DISEASES}

CD4 TRM have been investigated mainly for their role in providing protective immunity to pathogens that target specific tissues. However, there has been emerging evidence that this population may play a significant role in the pathogenesis of certain autoimmune, allergic, and atopic diseases. In mucosal sites, aberrant immune function and cross-reactivity of CD4 TRM in peripheral tissues are being investigated in inflammatory bowel disease (IBD) and asthma as possible causes of chronic or remitting immunopathology. In addition, there is evidence that CD4 TRM may play deleterious roles in inflammatory disorders of barrier surfaces such as skin. Understanding how CD4 TRM can promote undesirable inflammatory effects in the tissues is important to develop more targeted strategies for therapeutic control of inflammatory diseases.

Allergen-specific TRM populations can be established within lungs following local immune responses induced by exposure to allergens. As is the case following pathogen infection of barrier surfaces, a subset of the effector cells responding to the allergen is imprinted with a TRM phenotype and retained within the tissue. Memory $\mathrm{T}$ cells, particularly $\mathrm{T}_{\mathrm{H}} 2$ cells, are strongly involved in the pathogenesis of the chronic manifestations of allergic and atopic diseases (81-83); therefore, their localization at particular tissues make them prone to being reactivated and causing chronic disease. It will be interesting to determine whether CD4 TRM cells are established and maintained within the lung in mouse models of allergic asthma and their role in asthma pathogenesis and also in maintaining the hyper-responsive condition in the tissues. Pathogenic functions of lung CD4 TRM could involve immune cell recruitment into the lung airway upon secondary and chronic allergen exposure.

Inflammatory bowel disease is a chronic inflammatory disease of the gastrointestinal tract characterized by persistent inflammation of the gut or, in some cases, is manifested as a relapsing-remitting syndrome with flare-ups and resolution (84, 85 ). The chronic recurrence of disease and the restriction of the inflammation to the gastrointestinal tract suggest a role for resident memory $\mathrm{T}$ cells in the pathogenesis of IBD. $\mathrm{T}_{\mathrm{H}} 1$ and $\mathrm{T}_{\mathrm{H}} 17$ cells have both been implicated in the pathogenesis of the disease. In experimental models of IBD circulating colitogenic memory CD4 $\mathrm{T}$ cells required the presence of gut commensals to induce inflammation and IBD pathogenesis (86). In mouse models of IBD transfer experiments of gut CD4 TRM transferred disease to $\mathrm{RAG}^{-/-}$mice (87). This demonstrates resident memory CD4 $\mathrm{T}$-cell populations in the gut can propagate local inflammation leading to chronic IBD symptoms.

Psoriasis is another chronic inflammatory disease caused by T-cell responses at a barrier surface (88), with pathogenesis of relevance to inflammation in mucosal sites. Disease pathogenesis is driven by $\mathrm{T}$-cell migration into the epidermis and local production of inflammatory cytokines. $\mathrm{T}_{\mathrm{H}} 1$ and $\mathrm{T}_{\mathrm{H}} 17$ cells in particular have been linked to disease pathogenesis $(89,90)$. Skin resident memory $\mathrm{T}$ cells that are pathological are thought to influence disease recurrence (91). It was recently found that there were elevated numbers of CD8 and CD4 T cells in the dermis of resolved psoriasis lesions. These cells expressed markers associated with TRM (92), including CD103 and the $\alpha 1 \beta 1$ integrins expressed on epidermal CD4 T cells $(88,92)$. It is thus possible that chronic inflammation induces expression of integrins, which mediate cellcell interactions involved in T-cell retention in the epidermis and establishment of CD4 TRM. The harmful effects of TRM in cases of tissue-specific chronic inflammation, as seen in asthma and psoriasis, make TRM ideal targets for therapeutic interventions.

\section{ESTABLISHMENT AND MAINTENANCE OF CD4 TRM}

The factors involved in the establishment and maintenance of TRM populations within non-lymphoid tissues are not clearly understood. Entry of effector T cells into non-lymphoid mucosal sites is controlled by the expression of certain chemokine receptors, selectins, and integrins, which are universally upregulated after T-cell activation, regardless of the secondary lymphoid tissue where cells were activated (93). It has also been shown, however, that $\mathrm{T}$ cells primed by dendritic cells in certain lymphoid sites are programed to home specifically to certain tissues $(94,95)$. This tissue-specific homing is mediated through the expression of various integrins and chemokine receptors, which are involved in cell migration into specific tissues. For example, chemokine receptor chemokine receptor 9 (CCR9) and integrin $\alpha 4 \beta 7$ target $\mathrm{T}$ cells to the intestines $(96,97)$, cutaneous leukocyte antigen (CLA) targets cells to the skin (98), and lung DC promote effector T-cell homing to the lung through upregulation of CCR4 (99) (Figure 1). Whether these specific chemokine receptors persist in TRM remains to be established, and identifying specific tissue signatures for TRM in distinct sites is an active area of study in the field.

Effector $\mathrm{T}$ cells responding to infection/inflammation within non-lymphoid or mucosal tissues may further respond to inflammatory and/or tissue-specific environmental factors, which impart them with a resident memory phenotype. For CD8 T cells, expression of transforming growth factor-beta (TGF- $\beta$ ) within certain 


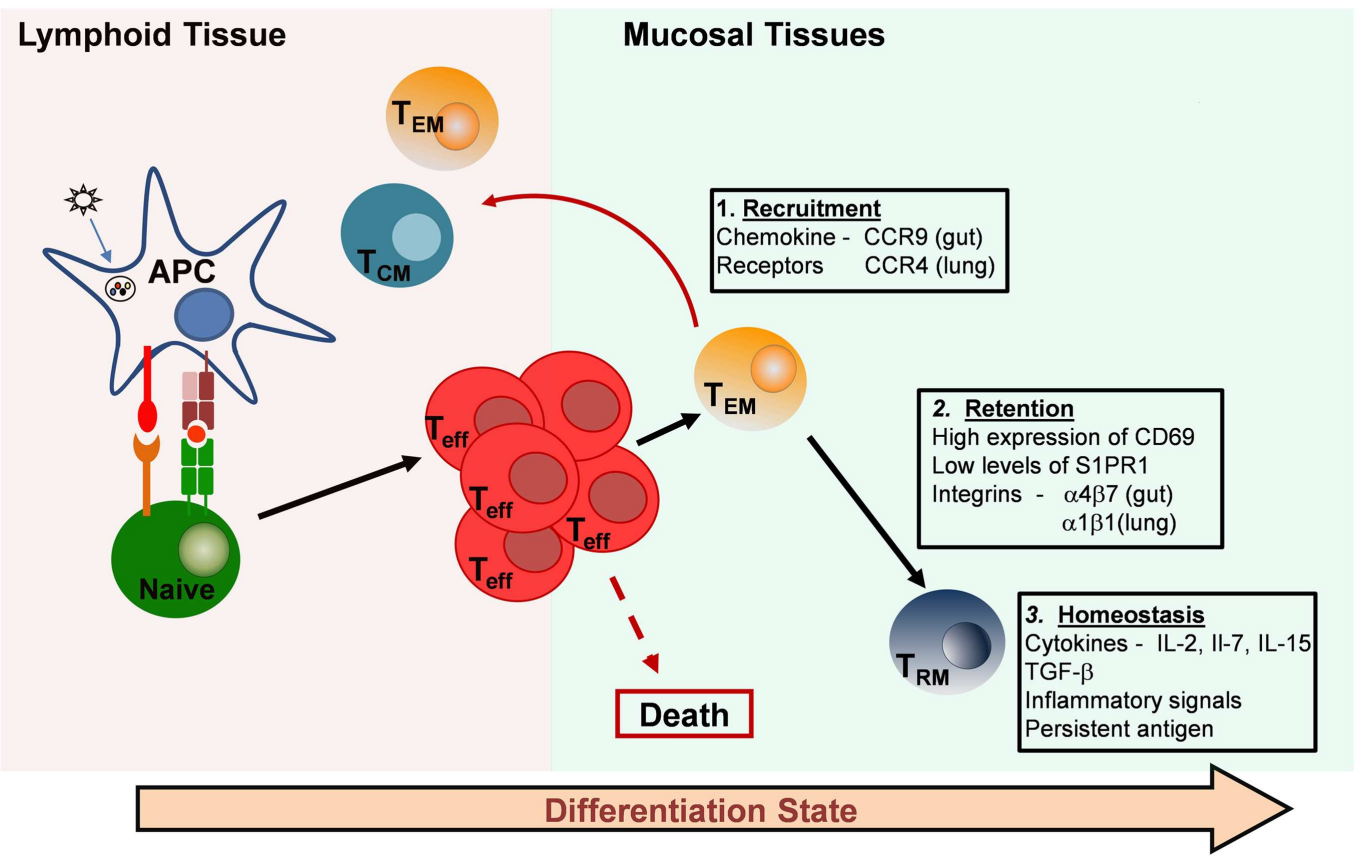

FIGURE 1 | Generation and maintenance of resident memory T-cell subsets. Resident memory $T$ cells in mucosal tissues are likely derived from recruited effector $T$ cells that originate in lymphoid organs. Effector cells can be imprinted with specific chemokine receptors that direct migration to individual tissues (Box 1). Most of the effector cells die, but a proportion of the effector or primed $T$ cells differentiates into long-lived resting memory $T$ cells. There are three major types: central-memory T cells (TCM), which migrate back to lymphoid tissue, effector-memory T cells (TEM), which circulate through peripheral tissues and tissue-resident memory $T$ cells (TRM), which are retained in mucosal tissue sites and take up long-term residence there without recirculating. Retention of TRM in peripheral tissues is thought to be mediated by the inhibition of egress through S1PR1 and by cell-cell interactions facilitated by integrin expression (Box 2). Maintenance and homeostasis of TRM in mucosal tissues may depend on pro-survival cytokines, constitutive low-level inflammation, and the persistence of antigen at the site (Box 3). tissues $(100,101)$ induces the expression of the mucosal integrin, $\alpha \mathrm{E}(\mathrm{CD} 103) \beta 7(102,103)$, which is responsible for retention of CD8 TRM in non-lymphoid tissues. CD4 TRM at mucosal sites express CD103 at a much lower frequency compared to CD8 TRM $(10,12)$ and may be maintained by other, unknown mechanisms. Other integrins may be involved in CD4 TRM retention and residence, which may represent a major difference between CD4 and CD8 TRM in the same tissue. It has been found that the vast majority of CD4 $\mathrm{T}$ cells persisting in the lung airways following influenza virus infection express the $\alpha 1 \beta 1$ integrin (VLA-1) while virus-specific cells in lymphoid sites have low expression of VLA-1 (37). Secondary infection with IAV revealed that these VLA-1 ${ }^{+}$ cells represented $80 \%$ of the early producers of IFN- $\gamma$ (37) suggesting that the $\alpha 1 \beta 1$ integrin might be a marker of lung CD4 TRM cells. CD11a or LFA-1 is also expressed at higher levels in lung CD4 TRM compared to circulating CD4 TEM $(12,13)$, and may also contribute to tissue retention.

The lectin CD69 is constitutively expressed on CD4 and CD8 TRM in all the tissues that have been described $(3,13,78,104)$. Traditionally, CD69 has been thought of as an early activation marker of $\mathrm{T}$ cells, being transiently upregulated early after activation through the T-cell receptor (105) or in response to proinflammatory cytokines, including type I interferons (IFN- $\alpha$ and IFN- $\beta$ ) and tumor necrosis factor- $\alpha(106,107)$. TRM cells in the lung constitutively express elevated levels of CD69 while T cells of the same specificities express low levels of CD69 in the lymph node and spleen (12). This local expression of CD69 by TRM may be the result of continued stimulation through encounters with persistent antigen at tissue sites, which has been observed following influenza virus $(108,109)$. We found that acquisition of TRM properties by effector cells adoptively transferred into congenic hosts in a manner that is independent of antigen (13). Induction of CD69 expression by T cells within tissues may therefore be the result of the environmental milieu associated with mucosal tissues, which is likely to be quite different from that of lymphoid organs.

Tonic signaling, through low levels of cytokines produced in response to environmental antigens, may also be involved in the differentiation of effector and effector-memory T cells into TRM. CD69 is thought to play a functional role in T-cell retention within tissues because of its regulation of sphingosine-1-phosphate receptor 1 (S1PR1) (110), which play a role in the egress of lymphocytes from certain tissues (111). A summary of processes involved in the recruitment, retention, and homeostasis of TRM in peripheral tissues is provided in Figure 1. Further studies are needed to define the exact molecular determinants of CD4 TRM establishment and maintenance. Defining the differences and similarities between the requirements for CD4 and CD8 TRM development and maintenance in tissues is also of utmost importance for the targeting of these new subsets by vaccines and therapeutics. 


\section{IMPLICATIONS FOR VACCINES}

As outlined in Table 1, there is now evidence for the presence CD4 TRM in multiple mucosal sites and roles for this subset in protection against pathogenic infections (Table 1). These findings present important implications for future therapeutic developments for promoting protective responses in situ. In the lung, generation of TRM populations targeting respiratory pathogens may significantly reduce the mortality and morbidity associated with these infections. In the case of influenza virus, the more common subunit vaccine is administered by intramuscular immunization, while the live attenuated influenza virus vaccine (LIAV), which is more commonly used for younger individuals, is administered intranasally. Both types of vaccine have been optimized for the generation of protective antibodies; however, both vaccines can induce circulating virus-specific $\mathrm{T}$ cells $(112,113)$ with the LIAV vaccine thought to generate more tissue-tropic T cells (114). A vaccine that induces memory $\mathrm{T}$ cells that recognize conserved epitopes from internal viral proteins could form the basis of a universal influenza virus vaccine. It may also be important that such a vaccine is administered in a manner that generates protective memory T-cell populations resident in the lung for optimal protection, likely via the intranasal route.

In the case of Mtb, current intramuscular bacille CalmetteGuérin (BCG) vaccination protocols show reliable protection during childhood but protection wanes during adulthood (115). This protection is mediated by $\mathrm{T}_{\mathrm{H}} 1$ memory cells; however, the exact effector mechanisms by which Th1 memory protect is not fully understood. Recent attempts to boost BCG protection by parenteral vaccination have yielded disappointing results. For example, clinical trials of the recombinant vaccinia virus booster vaccine, MVA85A, did not show better efficacy than the BCG vaccine (116) even though the new vaccine generates highly durable Mtb-specific $\mathrm{T}_{\mathrm{H}} 1$ responses (117). This result may have been foreshadowed by mouse experiments showing that parenteral boost with MVA85A after BCG priming showed no improvement in protection (118-121), compared with BCG vaccination alone, even with each vaccine showing high immunogenicity. Improved protection over BCG alone is only observed after multiple immunizations, which induce entry of cells into non-lymphoid tissues (122). These results suggest that memory T-cell mediated protection against respiratory $\mathrm{Mtb}$ infection may depend on the early in situ effector functions of TRM populations. Optimal protection may require both parenteral and mucosal administration of vaccines, which will generate both TRM and lymphoid memory populations.

The prevalence and protective capacities of TRM in the FRT has encouraged efforts for generating in situ vaccines for protection against sexually transmitted diseases. A new strategy for generating TRM in the FRT involves a "prime and pull" technique in which parenteral vaccination (prime) is combined with recruitment of activated $\mathrm{T}$ cells into the genital tract by local application of a chemokine (pull). When applied to the mouse HSV-2 infection model, this approach resulted in the recruitment but not retention of CD4 memory T cells, although HSV-2-specific CD8 TRM were generated (7). These results suggest that the establishment of CD4 TRM in the reproductive tract may require additional signals, such as those present during HSV infection $(44,123,124)$. In other studies for HIV vaccines, intranasal vaccination was found to generate higher anti-SIV T-cell responses in the colorectal mucosa, increased numbers of gut-tropic $\alpha 4 \beta 7$ cells in circulation, and a longer disease-free period compared to vaccination via the intramuscular route (125). These findings suggest some connections between mucosal sites important for assessing the optimal route of administration, and perhaps suggesting that a pull step may not be necessary. Further studies are needed to define the signals necessary for the local differentiation of CD4 T cells into TRM in order to develop vaccination and therapeutic protocols that harness the unique properties of these cells to prevent and fight site-specific infections.

\section{CONCLUDING REMARKS}

Compartmentalization of immunological memory in diverse nonlymphoid and mucosal tissues may be a central mechanism underlying the long-term persistence and efficacy of T-cell memory to systemic and site-specific pathogens. CD4 TRM in mucosal tissues may be optimally poised to orchestrate the immune response to recurring tissue-tropic infections. Developing vaccines that therefore generate this important population in targeted tissues should be a major focus of future research; however, greater understanding of the mechanisms involved in imprinting tissue-resident CD4 $\mathrm{T}$ cells is needed. Elucidating strategies to target TRM in mucosal and tissues will also allow for the development of therapeutics that reduce TRM populations in various tissues in instances of aberrant immune responses and immunopathology.

\section{REFERENCES}

1. Masopust D, Vezys V, Marzo AL, Lefrancois L. Preferential localization of effector memory cells in nonlymphoid tissue. Science (2001) 291(5512):2413-7. doi:10.1126/science.1058867

2. Klonowski KD, Williams KJ, Marzo AL, Blair DA, Lingenheld EG, Lefrancois L. Dynamics of blood-borne CD8 memory T cell migration in vivo. Immunity (2004) 20(5):551-62. doi:10.1016/S1074-7613(04)00103-7

3. Jiang X, Clark RA, Liu L, Wagers AJ, Fuhlbrigge RC, Kupper TS. Skin infection generates non-migratory memory CD8+ TRM cells providing global skin immunity. Nature (2012) 483(7388):227-31. doi:10.1038/nature10851

4. Schenkel JM, Fraser KA, Masopust D. Cutting edge: resident memory CD8 T cells occupy frontline niches in secondary lymphoid organs. J Immunol (2014) 192(7):2961-4. doi:10.4049/jimmunol.1400003

5. Wakim LM, Woodward-Davis A, Bevan MJ. Memory T cells persisting within the brain after local infection show functional adaptations to their tissue of residence. Proc Natl Acad Sci U S A (2010) 107(42):17872-9. doi:10.1073/pnas. 1010201107

6. Anderson KG, Sung H, Skon CN, Lefrancois L, Deisinger A, Vezys V, et al. Cutting edge: intravascular staining redefines lung CD8 $\mathrm{T}$ cell responses. J Immunol (2012) 189(6):2702-6. doi:10.4049/jimmunol.1201682

7. Shin H, Iwasaki A. A vaccine strategy that protects against genital herpes by establishing local memory T cells. Nature (2012) 491(7424):463-7. doi:10.1038/nature 11522

8. Masopust D, Picker LJ. Hidden memories: frontline memory $\mathrm{T}$ cells and early pathogen interception. J Immunol (2012) 188(12):5811-7. doi:10.4049/ jimmunol.1102695

9. Mueller SN, Gebhardt T, Carbone FR, Heath WR. Memory T cell subsets, migration patterns, and tissue residence. Annu Rev Immunol (2013) 31:137-61. doi:10.1146/annurev-immunol-032712-095954

10. Sathaliyawala T, Kubota M, Yudanin N, Turner D, Camp P, Thome JJ, et al. Distribution and compartmentalization of human circulating and tissue-resident memory T cell subsets. Immunity (2013) 38(1):187-97. doi:10.1016/j.immuni. 2012.09.020

11. Ganusov VV, De Boer RJ. Do most lymphocytes in humans really reside in the gut? Trends Immunol (2007) 28(12):514-8. doi:10.1016/j.it.2007.08.009 
12. Turner DL, Bickham KL, Thome JJ, Kim CY, D'Ovidio F, Wherry EJ, et al. Lung niches for the generation and maintenance of tissue-resident memory $\mathrm{T}$ cells. Mucosal Immunol (2014) 7(3):501-10. doi:10.1038/mi.2013.67

13. Teijaro JR, Turner D, Pham Q, Wherry EJ, Lefrancois L, Farber DL. Cutting edge: tissue-retentive lung memory CD4 T cells mediate optimal protection to respiratory virus infection. J Immunol (2011) 187(11):5510-4. doi:10.4049/jimmunol.1102243

14. Nakanishi Y, Lu B, Gerard C, Iwasaki A. CD8(+) T lymphocyte mobilization to virus-infected tissue requires CD4(+) T-cell help. Nature (2009) 462(7272):510-3. doi:10.1038/nature08511

15. Sakai S, Kauffman KD, Schenkel JM, McBerry CC, Mayer-Barber KD, Masopust D, et al. Cutting edge: control of Mycobacterium tuberculosis infection by a subset of lung parenchyma-homing CD4 T cells. J Immunol (2014) 192(7):2965-9. doi:10.4049/jimmunol.1400019

16. Sallusto F, Geginat J, Lanzavecchia A. Central memory and effector memory T cell subsets: function, generation, and maintenance. Annu Rev Immunol (2004) 22:745-63. doi:10.1146/annurev.immunol.22.012703.104702

17. Sallusto F, Lenig D, Forster R, Lipp M, Lanzavecchia A. Two subsets of memory T lymphocytes with distinct homing potentials and effector functions. Nature (1999) 401(6754):708-12. doi:10.1038/44385

18. Ahmadzadeh M, Hussain SF, Farber DL. Effector CD4 T cells are biochemically distinct from the memory subset: evidence for long-term persistence of effectors in vivo. J Immunol (1999) 163(6):3053-63.

19. Ahmadzadeh M, Hussain SF, Farber DL. Heterogeneity of the memory CD4 T cell response: persisting effectors and resting memory T cells. J Immunol (2001) 166(2):926-35. doi:10.4049/jimmunol.166.2.926

20. Usherwood EJ, Hogan RJ, Crowther G, Surman SL, Hogg TL, Altman JD, et al. Functionally heterogeneous CD8(+) T-cell memory is induced by Sendai virus infection of mice. J Virol (1999) 73(9):7278-86.

21. Reinhardt RL, Khoruts A, Merica R, Zell T, Jenkins MK. Visualizing the generation of memory CD4 T cells in the whole body. Nature (2001) 410(6824):101-5. doi:10.1038/35065111

22. Hogan RJ, Zhong W, Usherwood EJ, Cookenham T, Roberts AD, Woodland DL. Protection from respiratory virus infections can be mediated by antigenspecific CD4(+) T cells that persist in the lungs. J Exp Med (2001) 193(8):981-6. doi:10.1084/jem.193.8.981

23. Bingaman AW, Patke DS, Mane VR, Ahmadzadeh M, Ndejembi M, Bartlett ST, et al. Novel phenotypes and migratory properties distinguish memory CD4 T cell subsets in lymphoid and lung tissue. Eur J Immunol (2005) 35:3173-86. doi:10.1002/eji.200526004

24. Price PW, Cerny J. Characterization of CD4+ T cells in mouse bone marrow. I. Increased activated/memory phenotype and altered TCR Vbeta repertoire. Eur J Immunol (1999) 29(3):1051-6. doi:10.1002/(SICI)1521-4141(199903) 29:03<1051::AID-IMMU1051>3.0.CO;2-Y

25. Ibraghimov AR, Sacco RE, Sandor M, Iakoubov LZ, Lynch RG. Resident CD4+ alpha beta $\mathrm{T}$ cells of the murine female genital tract: a phenotypically distinct $\mathrm{T}$ cell lineage that rapidly proliferates in response to systemic $\mathrm{T}$ cell activation stimuli. Int Immunol (1995) 7(11):1763-9. doi:10.1093/intimm/7.11.1763

26. Bos JD, Hagenaars C, Das PK, Krieg SR, Voorn WJ, Kapsenberg ML. Predominance of "memory" T cells (CD4+, CDw29+) over "naïve" T cells (CD4+, CD45R+) in both normal and diseased human skin. Arch Dermatol Res (1989) 281(1):24-30. doi:10.1007/BF00424268

27. Campbell JJ, Murphy KE, Kunkel EJ, Brightling CE, Soler D, Shen Z, et al. CCR7 expression and memory $\mathrm{T}$ cell diversity in humans. J Immunol (2001) 166(2):877-84. doi:10.4049/jimmunol.166.2.877

28. Clark RA, Chong B, Mirchandani N, Brinster NK, Yamanaka K, Dowgiert RK, et al. The vast majority of CLA+ T cells are resident in normal skin. J Immunol (2006) 176(7):4431-9. doi:10.4049/jimmunol.176.7.4431

29. Kivisakk P, Mahad DJ, Callahan MK, Trebst C, Tucky B, Wei T, et al. Human cerebrospinal fluid central memory CD4+ T cells: evidence for trafficking through choroid plexus and meninges via P-selectin. Proc Natl Acad Sci U S A (2003) 100(14):8389-94. doi:10.1073/pnas.1433000100

30. Zaid A, Mackay LK, Rahimpour A, Braun A, Veldhoen M, Carbone FR, et al. Persistence of skin-resident memory T cells within an epidermal niche. Proc Natl Acad Sci U S A (2014) 111(14):5307-12. doi:10.1073/pnas.1322292111

31. Gebhardt T, Whitney PG, Zaid A, Mackay LK, Brooks AG, Heath WR, et al. Different patterns of peripheral migration by memory CD4+ and CD8+ T cells. Nature (2011) 477(7363):216-9. doi:10.1038/nature10339
32. Anderson KG, Mayer-Barber K, Sung H, Beura L, James BR, Taylor JJ, et al. Intravascular staining for discrimination of vascular and tissue leukocytes. Nat Protoc (2014) 9(1):209-22. doi:10.1038/nprot.2014.005

33. Turner DL, Gordon CL, Farber DL. Tissue-resident T cells, in situ immunity and transplantation. Immunol Rev (2014) 258(1):150-66. doi:10.1111/ imr. 12149

34. Purwar R, Campbell J, Murphy G, Richards WG, Clark RA, Kupper TS. Resident memory $\mathrm{T}$ cells $(\mathrm{T}(\mathrm{RM}))$ are abundant in human lung: diversity, function, and antigen specificity. PLoS One (2011) 6(1):e16245. doi:10.1371/journal.pone. 0016245

35. Herndler-Brandstetter D, Landgraf K, Jenewein B, Tzankov A, Brunauer R, Brunner S, et al. Human bone marrow hosts polyfunctional memory CD4+ and CD8+ T cells with close contact to IL-15-producing cells. J Immunol (2011) 186(12):6965-71. doi:10.4049/jimmunol.1100243

36. Farber DL, Yudanin NA, Restifo NP. Human memory T cells: generation, compartmentalization and homeostasis. Nat Rev Immunol (2014) 14(1):24-35. doi:10.1038/nri3567

37. Chapman TJ, Topham DJ. Identification of a unique population of tissuememory CD4+ T cells in the airways after influenza infection that is dependent on the integrin VLA-1. J Immunol (2010) 184(7):3841-9. doi:10.4049/ jimmunol.0902281

38. Tokoyoda K, Zehentmeier S, Hegazy AN, Albrecht I, Grun JR, Lohning M, et al. Professional memory CD4+ T lymphocytes preferentially reside and rest in the bone marrow. Immunity (2009) 30(5):721-30. doi:10.1016/j.immuni. 2009.03.015

39. de Bree GJ, Daniels H, Schilfgaarde M, Jansen HM, Out TA, van Lier RA, et al. Characterization of CD4+ memory $\mathrm{T}$ cell responses directed against common respiratory pathogens in peripheral blood and lung. J Infect Dis (2007) 195(11):1718-25. doi:10.1086/517612

40. Connor LM, Harvie MC, Rich FJ, Quinn KM, Brinkmann V, Le Gros G, et al. A key role for lung-resident memory lymphocytes in protective immune responses after BCG vaccination. Eur J Immunol (2010) 40(9):2482-92. doi:10.1002/eji.200940279

41. Thawer SG, Horsnell WG, Darby M, Hoving JC, Dewals B, Cutler AJ, et al. Lung-resident CD4(+) T cells are sufficient for IL-4Ralpha-dependent recall immunity to Nippostrongylus brasiliensis infection. Mucosal Immunol (2014) 7(2):239-48. doi:10.1038/mi.2013.40

42. Koelle DM, Corey L, Burke RL, Eisenberg RJ, Cohen GH, Pichyangkura R, et al. Antigenic specificities of human CD4+ T-cell clones recovered from recurrent genital herpes simplex virus type 2 lesions. J Virol (1994) 68(5): 2803-10.

43. Koelle DM, Frank JM, Johnson ML, Kwok WW. Recognition of herpes simplex virus type 2 tegument proteins by CD4 T cells infiltrating human genital herpes lesions. J Virol (1998) 72(9):7476-83.

44. Iijima N, Linehan MM, Zamora M, Butkus D, Dunn R, Kehry MR, et al. Dendritic cells and $\mathrm{B}$ cells maximize mucosal Th1 memory response to herpes simplex virus. J Exp Med (2008) 205(13):3041-52. doi:10.1084/jem.20082039

45. Marzo AL, Vezys V, Williams K, Tough DF, Lefrancois L. Tissue-level regulation of Th1 and Th2 primary and memory CD4 T cells in response to Listeria infection. J Immunol (2002) 168(9):4504-10. doi:10.4049/jimmunol.168.9.4504

46. Kawabe T, Sun SL, Fujita T, Yamaki S, Asao A, Takahashi T, et al. Homeostatic proliferation of naive CD4+ T cells in mesenteric lymph nodes generates guttropic Th17 cells. J Immunol (2013) 190(11):5788-98. doi:10.4049/jimmunol. 1203111

47. Cauley LS, Cookenham T, Miller TB, Adams PS, Vignali KM, Vignali DA, et al. Cutting edge: virus-specific CD4+ memory T cells in nonlymphoid tissues express a highly activated phenotype. J Immunol (2002) 169(12):6655-8. doi:10.4049/jimmunol.169.12.6655

48. Woodland DL, Kohlmeier JE. Migration, maintenance and recall of memory T cells in peripheral tissues. Nat Rev Immunol (2009) 9(3):153-61. doi:10.1038/nri2496

49. Wissinger EL, Stevens WW, Varga SM, Braciale TJ. Proliferative expansion and acquisition of effector activity by memory CD4+ $\mathrm{T}$ cells in the lungs following pulmonary virus infection. J Immunol (2008) 180(5):2957-66. doi:10.4049/jimmunol.180.5.2957

50. Walrath J, Zukowski L, Krywiak A, Silver RF. Resident Th1-like effector memory cells in pulmonary recall responses to Mycobacterium tuberculosis. Am J Respir Cell Mol Biol (2005) 33(1):48-55. doi:10.1165/rcmb.2005-0060OC 
51. Khader SA, Bell GK, Pearl JE, Fountain JJ, Rangel-Moreno J, Cilley GE, et al. IL-23 and IL-17 in the establishment of protective pulmonary CD4+ T cell responses after vaccination and during Mycobacterium tuberculosis challenge. Nat Immunol (2007) 8(4):369-77. doi:10.1038/ni1449

52. Chackerian AA, Perera TV, Behar SM. Gamma interferon-producing CD4+ T lymphocytes in the lung correlate with resistance to infection with Mycobacterium tuberculosis. Infect Immun (2001) 69(4):2666-74. doi:10.1128/IAI.69.4. 2666-2674.2001

53. McKinstry KK, Strutt TM, Kuang Y, Brown DM, Sell S, Dutton RW, et al. Memory CD4+ T cells protect against influenza through multiple synergizing mechanisms. J Clin Invest (2012) 122(8):2847-56. doi:10.1172/JCI63689

54. Teijaro JR, Verhoeven D, Page CA, Turner D, Farber DL. Memory CD4 T cells direct protective responses to influenza virus in the lungs through helperindependent mechanisms. J Virol (2010) 84(18):9217-26. doi:10.1128/JVI. 01069-10

55. Walrath JR, Silver RF. The alpha4betal integrin in localization of Mycobacterium tuberculosis-specific T helper type 1 cells to the human lung. Am J Respir Cell Mol Biol (2011) 45(1):24-30. doi:10.1165/rcmb.2010-0241OC

56. Klein RS, Harris CA, Small CB, Moll B, Lesser M, Friedland GH. Oral candidiasis in high-risk patients as the initial manifestation of the acquired immunodeficiency syndrome. N Engl J Med (1984) 311(6):354-8. doi:10.1056/ NEJM198408093110602

57. Clift RA. Candidiasis in the transplant patient. Am J Med (1984) 77(4D):34-8.

58. Eriksson K, Bellner L, Gorander S, Lowhagen GB, Tunback P, Rydberg K, et al. $\mathrm{CD} 4(+)$ T-cell responses to herpes simplex virus type 2 (HSV-2) glycoprotein $\mathrm{G}$ are type specific and differ in symptomatic and asymptomatic HSV-2infected individuals. J Gen Virol (2004) 85(Pt 8):2139-47. doi:10.1099/vir.0. 79978-0

59. Harandi AM, Svennerholm B, Holmgren J, Eriksson K. Differential roles of B cells and IFN-gamma-secreting CD4(+) T cells in innate and adaptive immune control of genital herpes simplex virus type 2 infection in mice. J Gen Virol (2001) 82(Pt 4):845-53.

60. Koelle DM, Schomogyi M, Corey L. Antigen-specific T cells localize to the uterine cervix in women with genital herpes simplex virus type 2 infection. J Infect Dis (2000) 182(3):662-70. doi:10.1086/315749

61. Feinen B, Jerse AE, Gaffen SL, Russell MW. Critical role of Th17 responses in a murine model of Neisseria gonorrhoeae genital infection. Mucosal Immunol (2010) 3(3):312-21. doi:10.1038/mi.2009.139

62. Scurlock AM, Frazer LC, Andrews CW Jr, O’Connell CM, Foote IP, Bailey SL, et al. Interleukin-17 contributes to generation of Th1 immunity and neutrophil recruitment during Chlamydia muridarum genital tract infection but is not required for macrophage influx or normal resolution of infection. Infect Immun (2011) 79(3):1349-62. doi:10.1128/IAI.00984-10

63. Gondek DC, Olive AJ, Stary G, Starnbach MN. CD4+ T cells are necessary and sufficient to confer protection against Chlamydia trachomatis infection in the murine upper genital tract. J Immunol (2012) 189(5):2441-9. doi:10.4049/jimmunol.1103032

64. Pietrella D, Rachini A, Pines M, Pandey N, Mosci P, Bistoni F, et al. Th17 cells and IL-17 in protective immunity to vaginal candidiasis. PLoS One (2011) 6(7):e22770. doi:10.1371/journal.pone.0022770

65. Hu J, Gardner MB, Miller CJ. Simian immunodeficiency virus rapidly penetrates the cervicovaginal mucosa after intravaginal inoculation and infects intraepithelial dendritic cells. J Virol (2000) 74(13):6087-95. doi:10.1128/JVI. 74.13.6087-6095.2000

66. Miller CJ, Li Q, Abel K, Kim EY, Ma ZM, Wietgrefe S, et al. Propagation and dissemination of infection after vaginal transmission of simian immunodeficiency virus. J Virol (2005) 79(14):9217-27. doi:10.1128/JVI.79.14.9217-9227.2005

67. Shale M, Schiering C, Powrie F. CD4(+) T-cell subsets in intestinal inflammation. Immunol Rev (2013) 252(1):164-82. doi:10.1111/imr.12039

68. Mowat AM. Anatomical basis of tolerance and immunity to intestinal antigens. Nat Rev Immunol (2003) 3(4):331-41. doi:10.1038/nri1057

69. Eberl G, Lochner M. The development of intestinal lymphoid tissues at the interface of self and microbiota. Mucosal Immunol (2009) 2(6):478-85. doi:10.1038/mi.2009.114

70. Kilshaw PJ, Baker KC. A unique surface antigen on intraepithelial lymphocytes in the mouse. Immunol Lett (1988) 18(2):149-54. doi:10.1016/0165-2478(88) 90056-9

71. Cerf-Bensussan N, Jarry A, Brousse N, Lisowska-Grospierre B, Guy-Grand D, Griscelli C. A monoclonal antibody (HML-1) defining a novel membrane molecule present on human intestinal lymphocytes. Eur J Immunol (1987) 17(9):1279-85. doi:10.1002/eji.1830170910

72. Russell GJ, Parker CM, Cepek KL, Mandelbrot DA, Sood A, Mizoguchi E, et al. Distinct structural and functional epitopes of the alpha E beta 7 integrin. Eur J Immunol (1994) 24(11):2832-41. doi:10.1002/eji.1830241138

73. Ivanov II, Frutos Rde L, Manel N, Yoshinaga K, Rifkin DB, Sartor RB, et al. Specific microbiota direct the differentiation of IL-17-producing T-helper cells in the mucosa of the small intestine. Cell Host Microbe (2008) 4(4):337-49. doi:10.1016/j.chom.2008.09.009

74. Ivanov II, Atarashi K, Manel N, Brodie EL, Shima T, Karaoz U, et al. Induction of intestinal Th17 cells by segmented filamentous bacteria. Cell (2009) 139(3):485-98. doi:10.1016/j.cell.2009.09.033

75. Round JL, Mazmanian SK. Inducible Foxp3+ regulatory T-cell development by a commensal bacterium of the intestinal microbiota. Proc Natl Acad Sci US A (2010) 107(27):12204-9. doi:10.1073/pnas.0909122107

76. Atarashi K, Tanoue T, Shima T, Imaoka A, Kuwahara T, Momose Y, et al. Induction of colonic regulatory $\mathrm{T}$ cells by indigenous Clostridium species. Science (2011) 331(6015):337-41. doi:10.1126/science.1198469

77. Atarashi K, Tanoue T, Oshima K, Suda W, Nagano Y, Nishikawa H, et al. Treg induction by a rationally selected mixture of Clostridia strains from the human microbiota. Nature (2013) 500(7461):232-6. doi:10.1038/nature12331

78. Masopust D, Choo D, Vezys V, Wherry EJ, Duraiswamy J, Akondy R, et al. Dynamic T cell migration program provides resident memory within intestinal epithelium. J Exp Med (2010) 207(3):553-64. doi:10.1084/jem.20090858

79. Poussier P, Edouard P, Lee C, Binnie M, Julius M. Thymus-independent development and negative selection of $\mathrm{T}$ cells expressing $\mathrm{T}$ cell receptor alpha/beta in the intestinal epithelium: evidence for distinct circulation patterns of gut- and thymus-derived T lymphocytes. J Exp Med (1992) 176(1):187-99. doi:10.1084/jem.176.1.187

80. Mora JR. Homing imprinting and immunomodulation in the gut: role of dendritic cells and retinoids. Inflamm Bowel Dis (2008) 14(2):275-89. doi:10.1002/ibd.20280

81. Lloyd CM, Hessel EM. Functions of T cells in asthma: more than just $\mathrm{T}(\mathrm{H}) 2$ cells. Nat Rev Immunol (2010) 10(12):838-48. doi:10.1038/nri2870

82. Wang YH, Voo KS, Liu B, Chen CY, Uygungil B, Spoede W, et al. A novel subset of CD4(+) T(H)2 memory/effector cells that produce inflammatory IL-17 cytokine and promote the exacerbation of chronic allergic asthma. J Exp Med (2010) 207(11):2479-91. doi:10.1084/jem.20101376

83. Holt PG, Strickland DH, Bosco A, Jahnsen FL. Pathogenic mechanisms of allergic inflammation: atopic asthma as a paradigm. Adv Immunol (2009) 104:51-113. doi:10.1016/S0065-2776(08)04003-0

84. Baumgart DC, Sandborn WJ. Inflammatory bowel disease: clinical aspects and established and evolving therapies. Lancet (2007) 369(9573):1641-57. doi:10.1016/S0140-6736(07)60751-X

85. Xavier RJ, Podolsky DK. Unravelling the pathogenesis of inflammatory bowel disease. Nature (2007) 448(7152):427-34. doi:10.1038/nature06005

86. Nemoto Y, Kanai T, Kameyama K, Shinohara T, Sakamoto N, Totsuka T, et al. Long-lived colitogenic CD4+ memory T cells residing outside the intestine participate in the perpetuation of chronic colitis. J Immunol (2009) 183(8):5059-68. doi:10.4049/jimmunol.0803684

87. Takahara M, Nemoto Y, Oshima S, Matsuzawa Y, Kanai T, Okamoto R, et al. IL-7 promotes long-term in vitro survival of unique long-lived memory subset generated from mucosal effector memory CD4+ T cells in chronic colitis mice. Immunol Lett (2013) 156(1-2):82-93. doi:10.1016/j.imlet.2013.09.001

88. Conrad C, Boyman O, Tonel G, Tun-Kyi A, Laggner U, de Fougerolles A, et al. Alpha1betal integrin is crucial for accumulation of epidermal $\mathrm{T}$ cells and the development of psoriasis. Nat Med (2007) 13(7):836-42. doi:10.1038/ nm 1605

89. Lowes MA, Kikuchi T, Fuentes-Duculan J, Cardinale I, Zaba LC, Haider AS, et al. Psoriasis vulgaris lesions contain discrete populations of Th1 and Th17 T cells. J Invest Dermatol (2008) 128(5):1207-11. doi:10.1038/sj.jid.5701213

90. Lewis BJ, Rajpara S, Haggart AM, Wilson HM, Barker RN, Ormerod AD. Predominance of activated, clonally expanded T helper type 17 cells within the CD4+ T cell population in psoriatic lesions. Clin Exp Immunol (2013) 173(1):38-46. doi:10.1111/cei.12086

91. Boyman O, Hefti HP, Conrad C, Nickoloff BJ, Suter M, Nestle FO. Spontaneous development of psoriasis in a new animal model shows an essential role for resident T cells and tumor necrosis factor-alpha. J Exp Med (2004) 199(5):731-6. doi:10.1084/jem.20031482 
92. Cheuk S, Wiken M, Blomqvist L, Nylen S, Talme T, Stahle M, et al. Epidermal Th22 and Tc17 cells form a localized disease memory in clinically healed psoriasis. J Immunol (2014) 192(7):3111-20. doi:10.4049/jimmunol.1302313

93. Masopust D, Vezys V, Usherwood EJ, Cauley LS, Olson S, Marzo AL, et al. Activated primary and memory CD8 T cells migrate to nonlymphoid tissues regardless of site of activation or tissue of origin. J Immunol (2004) 172(8):4875-82. doi:10.4049/jimmunol.172.8.4875

94. Agace WW. Tissue-tropic effector T cells: generation and targeting opportunities. Nat Rev Immunol (2006) 6(9):682-92. doi:10.1038/nri1869

95. Lefrancois L, Puddington L. Intestinal and pulmonary mucosal T cells: local heroes fight to maintain the status quo. Annu Rev Immunol (2006) 24:681-704. doi:10.1146/annurev.immunol.24.021605.090650

96. Iwata M, Hirakiyama A, Eshima Y, Kagechika H, Kato C, Song SY. Retinoic acid imprints gut-homing specificity on T cells. Immunity (2004) 21(4):527-38. doi:10.1016/j.immuni.2004.08.011

97. Kunkel EJ, Campbell JJ, Haraldsen G, Pan J, Boisvert J, Roberts AI, et al. Lymphocyte CC chemokine receptor 9 and epithelial thymus-expressed chemokine (TECK) expression distinguish the small intestinal immune compartment: epithelial expression of tissue-specific chemokines as an organizing principle in regional immunity. J Exp Med (2000) 192(5):761-8. doi:10.1084/jem.192.5.761

98. Berg EL, Yoshino T, Rott LS, Robinson MK, Warnock RA, Kishimoto TK, et al. The cutaneous lymphocyte antigen is a skin lymphocyte homing receptor for the vascular lectin endothelial cell-leukocyte adhesion molecule 1. J Exp Med (1991) 174(6):1461-6. doi:10.1084/jem.174.6.1461

99. Mikhak Z, Strassner JP, Luster AD. Lung dendritic cells imprint T cell lung homing and promote lung immunity through the chemokine receptor CCR4. J Exp Med (2013) 210(9):1855-69. doi:10.1084/jem.20130091

100. Kane CJ, Knapp AM, Mansbridge JN, Hanawalt PC. Transforming growth factor-beta 1 localization in normal and psoriatic epidermal keratinocytes in situ. J Cell Physiol (1990) 144(1):144-50. doi:10.1002/jcp.1041440119

101. Koyama SY, Podolsky DK. Differential expression of transforming growth factors alpha and beta in rat intestinal epithelial cells. J Clin Invest (1989) 83(5):1768-73. doi:10.1172/JCI114080

102. Wang D, Yuan R, Feng Y, El-Asady R, Farber DL, Gress RE, et al. Regulation of CD103 expression by CD8+ T cells responding to renal allografts. J Immunol (2004) 172(1):214-21. doi:10.4049/jimmunol.172.1.214

103. Lee YT, Suarez-Ramirez JE, Wu T, Redman JM, Bouchard K, Hadley GA, et al. Environmental and antigen receptor-derived signals support sustained surveillance of the lungs by pathogen-specific cytotoxic T lymphocytes. J Virol (2011) 85(9):4085-94. doi:10.1128/JVI.02493-10

104. Masopust D, Vezys V, Wherry EJ, Barber DL, Ahmed R. Cutting edge: gut microenvironment promotes differentiation of a unique memory CD8 T cell population. J Immunol (2006) 176(4):2079-83. doi:10.4049/jimmunol.176.4. 2079

105. Ziegler SF, Ramsdell F, Alderson MR. The activation antigen CD69. Stem Cells (1994) 12(5):456-65. doi:10.1002/stem.5530120502

106. Freeman BE, Hammarlund E, Raue HP, Slifka MK. Regulation of innate CD8+ T-cell activation mediated by cytokines. Proc Natl Acad Sci U S A (2012) 109(25):9971-6. doi:10.1073/pnas.1203543109

107. Sun S, Zhang X, Tough DF, Sprent J. Type I interferon-mediated stimulation of T cells by CpG DNA. J Exp Med (1998) 188(12):2335-42. doi:10.1084/jem. 188.12.2335

108. Zammit DJ, Turner DL, Klonowski KD, Lefrancois L, Cauley LS. Residual antigen presentation after influenza virus infection affects CD8 T cell activation and migration. Immunity (2006) 24(4):439-49. doi:10.1016/j.immuni.2006.01.015

109. Kim TS, Hufford MM, Sun J, Fu YX, Braciale TJ. Antigen persistence and the control of local $\mathrm{T}$ cell memory by migrant respiratory dendritic cells after acute virus infection. J Exp Med (2010) 207(6):1161-72. doi:10.1084/jem. 20092017

110. Bankovich AJ, Shiow LR, Cyster JG. CD69 suppresses sphingosine 1phosophate receptor-1 (S1P1) function through interaction with membrane helix 4. J Biol Chem (2010) 285(29):22328-37. doi:10.1074/jbc.M110.123299

111. Matloubian M, Lo CG, Cinamon G, Lesneski MJ, Xu Y, Brinkmann V, et al. Lymphocyte egress from thymus and peripheral lymphoid organs is dependent on S1P receptor 1. Nature (2004) 427(6972):355-60. doi:10.1038/ nature 02284

112. Guthrie T, Hobbs CG, Davenport V, Horton RE, Heyderman RS, Williams NA. Parenteral influenza vaccination influences mucosal and systemic T cellmediated immunity in healthy adults. J Infect Dis (2004) 190(11):1927-35. doi:10.1086/425517
113. Lanthier PA, Huston GE, Moquin A, Eaton SM, Szaba FM, Kummer LW, et al. Live attenuated influenza vaccine (LAIV) impacts innate and adaptive immune responses. Vaccine (2011) 29(44):7849-56. doi:10.1016/j.vaccine.2011.07.093

114. Hammitt LL, Bartlett JP, Li S, Rahkola J, Lang N, Janoff EN, et al. Kinetics of viral shedding and immune responses in adults following administration of cold-adapted influenza vaccine. Vaccine (2009) 27(52):7359-66. doi:10.1016/j.vaccine.2009.09.041

115. Trunz BB, Fine P, Dye C. Effect of BCG vaccination on childhood tuberculous meningitis and miliary tuberculosis worldwide: a meta-analysis and assessment of cost-effectiveness. Lancet (2006) 367(9517):1173-80. doi:10.1016/S01406736(06)68507-3

116. Tameris MD, Hatherill M, Landry BS, Scriba TJ, Snowden MA, Lockhart S, et al. Safety and efficacy of MVA85A, a new tuberculosis vaccine, in infants previously vaccinated with BCG: a randomised, placebo-controlled phase $2 \mathrm{~b}$ trial. Lancet (2013) 381(9871):1021-8. doi:10.1016/S0140-6736(13)60177-4

117. Tameris M, Geldenhuys H, Luabeya AK, Smit E, Hughes JE, Vermaak S, et al. The candidate TB vaccine, MVA85A, induces highly durable Th1 responses. PLoS One (2014) 9(2):e87340. doi:10.1371/journal.pone.0087340

118. Tchilian EZ, Desel C, Forbes EK, Bandermann S, Sander CR, Hill AV, et al. Immunogenicity and protective efficacy of prime-boost regimens with recombinant (delta)ureC hly+ Mycobacterium bovis BCG and modified vaccinia virus Ankara expressing $M$. tuberculosis antigen 85A against murine tuberculosis. Infect Immun (2009) 77(2):622-31. doi:10.1128/IAI.00685-08

119. Williams A, Hatch GJ, Clark SO, Gooch KE, Hatch KA, Hall GA, et al. Evaluation of vaccines in the EU TB vaccine cluster using a guinea pig aerosol infection model of tuberculosis. Tuberculosis (Edinb) (2005) 85(1-2):29-38. doi:10.1016/j.tube.2004.09.009

120. Vordermeier HM, Villarreal-Ramos B, Cockle PJ, McAulay M, Rhodes SG, Thacker T, et al. Viral booster vaccines improve Mycobacterium bovis BCG-induced protection against bovine tuberculosis. Infect Immun (2009) 77(8):3364-73. doi:10.1128/IAI.00287-09

121. Verreck FA, Vervenne RA, Kondova I, van Kralingen KW, Remarque EJ, Braskamp G, et al. MVA.85A boosting of BCG and an attenuated, phoP deficient $M$. tuberculosis vaccine both show protective efficacy against tuberculosis in rhesus macaques. PLoS One (2009) 4(4):e5264. doi:10.1371/journal.pone. 0005264

122. Lin PL, Dietrich J, Tan E, Abalos RM, Burgos J, Bigbee C, et al. The multistage vaccine $\mathrm{H} 56$ boosts the effects of BCG to protect cynomolgus macaques against active tuberculosis and reactivation of latent Mycobacterium tuberculosis infection. J Clin Invest (2012) 122(1):303-14. doi:10.1172/JCI46252

123. Zhu J, Hladik F, Woodward A, Klock A, Peng T, Johnston C, et al. Persistence of HIV-1 receptor-positive cells after HSV-2 reactivation is a potential mechanism for increased HIV-1 acquisition. Nat Med (2009) 15(8):886-92 doi:10.1038/nm.2006

124. Huang W, Hu K, Luo S, Zhang M, Li C, Jin W, et al. Herpes simplex virus type 2 infection of human epithelial cells induces CXCL9 expression and CD4+ $\mathrm{T}$ cell migration via activation of $\mathrm{p} 38$-CCAAT/enhancer-binding protein-beta pathway. J Immunol (2012) 188(12):6247-57. doi:10.4049/jimmunol.1103706

125. Manrique M, Kozlowski PA, Wang SW, Wilson RL, Micewicz E, Montefiori DC, et al. Nasal DNA-MVA SIV vaccination provides more significant protection from progression to AIDS than a similar intramuscular vaccination. Mucosal Immunol (2009) 2(6):536-50. doi:10.1038/mi.2009.103

Conflict of Interest Statement: The authors declare that the research was conducted in the absence of any commercial or financial relationships that could be construed as a potential conflict of interest.

Received: 30 May 2014; accepted: 30 June 2014; published online: 14 July 2014. Citation: Turner DL and Farber DL (2014) Mucosal resident memory CD4 $T$ cells in protection and immunopathology. Front. Immunol. 5:331. doi: 10.3389/fimmu.2014.00331

This article was submitted to Immunological Memory, a section of the journal Frontiers in Immunology.

Copyright (c) 2014 Turner and Farber. This is an open-access article distributed under the terms of the Creative Commons Attribution License (CC BY). The use, distribution or reproduction in other forums is permitted, provided the original author (s) or licensor are credited and that the original publication in this journal is cited, in accordance with accepted academic practice. No use, distribution or reproduction is permitted which does not comply with these terms. 